\title{
AFTERSHOCK OBSERVATION OF A SOUTHEASTERN NEVADA EARTHQUAKE AT CALIENTE
}

\author{
Kei TAKANO*, Hiroyuki HamaguChI**, and Hikaru WATANABE***
}

(Received December 19, 1972; Revised February 26, 1973)

\begin{abstract}
Many aftershocks of very small magnitude were detected at Caliente, Nevada, seven and a half months after the southeastern Nevada earthquake of August 16, 1966.

An observation was made for 10 days at Caliente in the framework of the Japan-U.S. microearthquake program. Observed were 2600 events per day where the $S$ - $P$ time was shorter than 2 seconds. A $b$ value was determined to be 1.10 for the magnitude range from -1.1 to 0.2 .
\end{abstract}

\section{Introduction}

The present report is concerned with the observation of aftershocks of a southeastern Nevada earthquake that occurred on August 16, 1966, at Caliente, Nevada. According to the Bulletin of the U.S.C.G.S., the epicenter of the main shock is located at $37.4^{\circ} \mathrm{N}$ and $114.2^{\circ} \mathrm{W}$, and $m_{b}$ and its focal depth were 5.6 and $33 \mathrm{~km}$, respectively.

The southwestern part of Nevada is a region of high seismicity. The most active seismic zone extends from Ventura on the coast of southern California to near Winnemucca in north-central Nevada (RYAll et al., 1966). The Dixie Valley-Fairview Peak earthquake of magnitude 7.1 occurred in this zone in 1954. The seismicity of the southeastern part of Nevada is, on the contrary, rather low, as shown in the "Catalog of Nevada Earthquakes of 1852-1960" compiled by SLEmmons et al. (1965). Only two earthquakes for this period occurred, one in 1941 and the other in 1943, both of magnitude 4.

An aftershock observation was made in early April of 1967, in the framework of the Japan-U.S. joint microearthquake program. Researchers from the University of Nevada and the Lamont-Doherty Geological Observatory (A. Ryall, G. Boucher, L. Seeber) cooperated with us. The present report is based on the data collected by the Japanese group alone.

It should be noted that BouCHER et al. (1967) operated a seismometers 10 days after the main shock at the same place and recorded more than 8000 aftershocks per day. An epicenter map of aftershocks of this earthquake was prepared by Cook et al. (1968).

\section{Equipment and Method of Observation}

The three groups (University of Nevada group, Lamont-Doherty Geological

* Geophysical Institute, Faculty of Science, University of Tokyo.

** Geophysical Institute, Faculty of Science, Tohoku University.

*** Abuyama Seismological Observatory, Faculty of Science, Kyoto University. 
Observatory group and our group) operated their own equipment: data recorders with an FM system in a trailer operated by the University of Nevada, back-pack seismometers operated by the Lamont-Doherty Geological Observatory, and data recorders with a direct recording system operated by us.

Two data recorders were installed by us at two fixed stations marked by $J A$ and $J T$

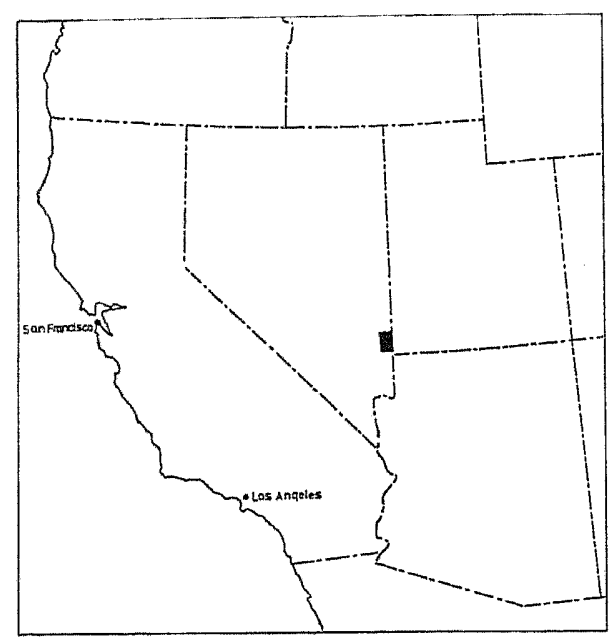

Fig. 1. Map of location.

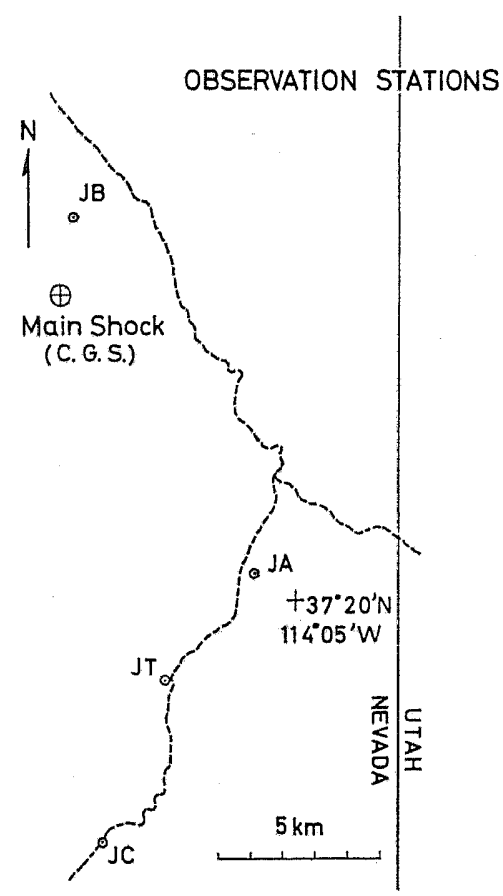

Fig. 2. Map of observation points. 
in Fig. 2. Another recorder was first installed at $J B$ and moved to $J C$ after the observation for three days at $J B$. Station $J C$ is in a desert area. The seismometers and amplifiers are those generally used for explosion seismology in Japan. In consideration of low

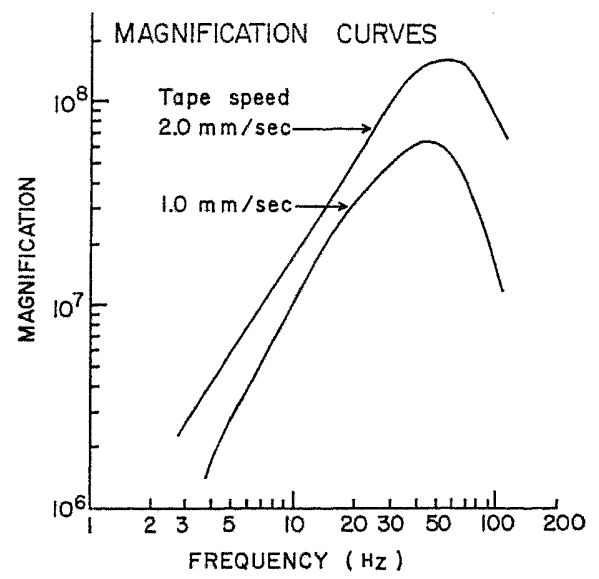

Fig. 3. The frequency response curve of the seismometer and data recorder.

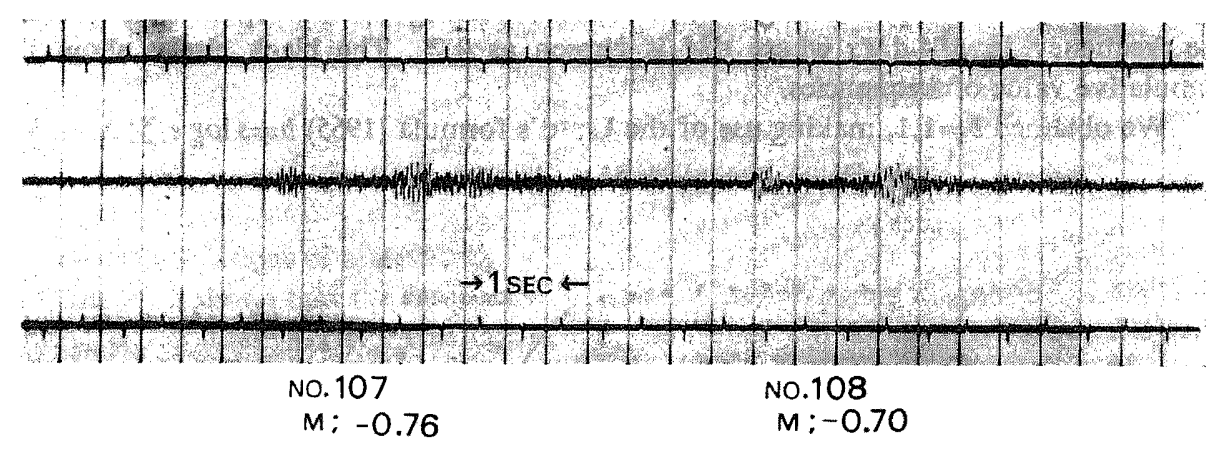

Fig. 4. An example of records at station $J A$.

ground noises in this region, a low-noise pre-amplifier with a sensitivity of about $30 \mathrm{db}$ was used. The frequency characteristic curve of the seismometer with amplifier and data recorder is shown in Fig. 3.

A recording speed of $1 \mathrm{~mm}$ or $2 \mathrm{~mm}$ per second on magnetic tape was used, while the playback speed on a visigraph was 20,50 or 100 times faster than the recording speed. An example of the record is shown in Fig. 4.

\section{Result and Discussion}

\subsection{Number of earthquakes}

The fixed station $J A$ in Fig. 2 had the best condition of all stations because of the low ground noises. 
The amplifier sensitivity was about $110 \mathrm{db}$, and the total magnification was about $5 \times 10^{7}$ at $30 \mathrm{~Hz}$. The number of events was counted on the records of the visigraph. About 2600 events per day were recorded on the magnetic tape at station $J A$. The number of events observed decreases rapidly with the increasing epicentral distance. At station $J T, 5.6 \mathrm{~km}$ apart from station $J A$, the number of events per day was $1 / 10$ of that at $J A$ and $1 / 45$ at $J C, 13 \mathrm{~km}$ apart from station $J A$. A crude estimation gives a relation $N \propto D^{-1.5}$. All the above stations are situated at the east end of Basin and Range Province which are well known as high attenuation zones of seismic waves.

BOUCHER et al. (1967) observed 8000 events per day 10 days after the main shock as mentioned above. Moreover, it should be noted that 2600 events occurred per day at almost the same magnification as that of BOUCHER et al. (1967) about seven and a half months after the main shock. This area might be a rather high aftershock activity region.

\subsection{Magnitude}

To determine the earthquake magnitude, we used the WATANABE's formula (1971), $M=1.18 \log A_{v}+2.04 \log r+2.94$, where $A_{v}$ is the velocity amplitude in $\mathrm{cm} / \mathrm{sec}, r$ is the hypocentral distance in $\mathrm{km}$, and $r=7.8 \times(S-P)$ time. If the RICHTER's formula (1935) is used instead of the above one, the result of Magnitude-frequency distributions changes very little.

The magnitude of each of about 500 events is calculated according to this formula. The frequency $N$ versus the magnitude $M$ is shown in Fig. 5. The open circle indicates the frequency in $M+\mathrm{d} M$, where $\mathrm{d} M$ is chosen as 0.2 . The black circles show the cumulative value of frequencies.

We obtained $b=1.1$, making use of the UTsu's formula (1965) $b=s \log e / \sum M-s M_{8}$,

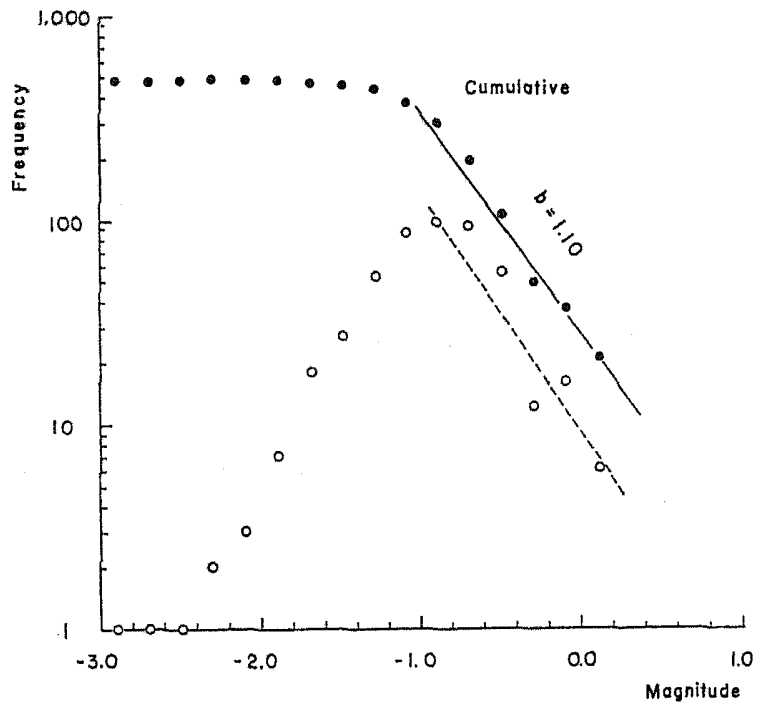

Fig. 5. Frequency distribution of magnitude. Full line is determined by black circles, broken line is determined by open circles. 
where $s$ is the total number of earthquakes of magnitude equal to or larger than $M_{s}$, and $\sum M$ is the sum of magnitudes of the $s$ earthquakes. The smallest magnitude of the earthquakes used in this calculation is -1.1 , while the smallest one of the earthquakes recorded is about -3.0 . The linear relation between $\log N$ and $M$ (i.e., $\log N=a-b M$ ) is valid down to this smallest magnitude. It is parenthetically pointed out that the apparatus used in this observation is of higher sensitivity and higher $S / N$ than those used

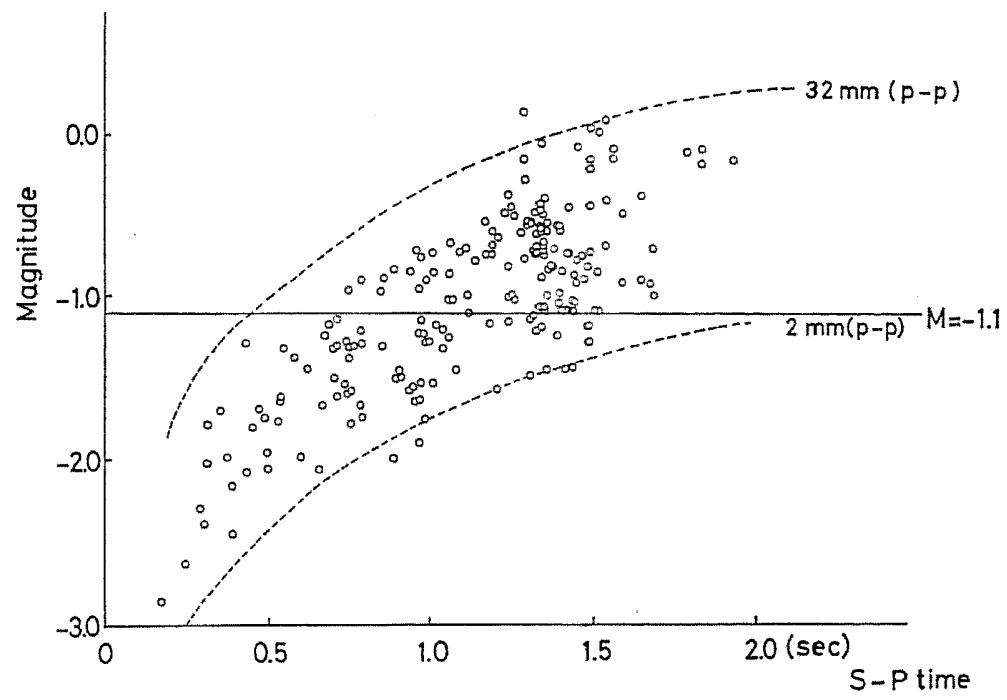

Fig. 6. $S-P$ times vs. Magnitude of aftershocks.

in usual observations of aftershocks.

Figure 5 shows that the frequency decreases with decreasing magnitude, if the magnitude is less than -1.1 . This decrease of the frequency reflects the limit of the detection capability at station $J A$. The magnitude versus $S-P$ time is illustrated in Fig. 6 . All the events are found between the $32 \mathrm{~mm}$ line and the $2 \mathrm{~mm}$ line. The $32 \mathrm{~mm}$ line is the saturation line of amplitude of event on the record and the $2 \mathrm{~mm}$ line is the limit imposed by the ground noises. Under $2 \mathrm{~mm}$ line, no events can be detected because of ground noises, which is the reason why the frequency decreases with decreasing magnitude for magnitude less than -1.1 as mentioned above.

The level of ground noises was very low at night. Its minimum value was about $0.6 \mu \mathrm{cm} / \mathrm{sec}$ at $30 \mathrm{~Hz}$, and the ratio between the noise levels during the day and during the night was about $4: 1$. The minimum value of noise was 6 times as large as that of Dixie Valley-Fairview Peak in Nevada observed by OLIVER et al. (1966). The noise level obtained by Oliver et al. was much smaller than ever observed in Japan and U.S.A.

\subsection{Distribution of aftershock foci}

From the records of three stations $J A, J B$ and $J T$ in Fig. 2, aftershock foci were determined, by using the $P$ arrival time and the $S-P$ time at each station, and by assuming a homogeneous layer of $V_{p}=5.5 \mathrm{~km} / \mathrm{sec}$ and $V_{p} / V_{s}=1.72$. Because of a great distance of $12 \mathrm{~km}$ between $J A$ and $J B$, seismic signals have no more correspondence between the 


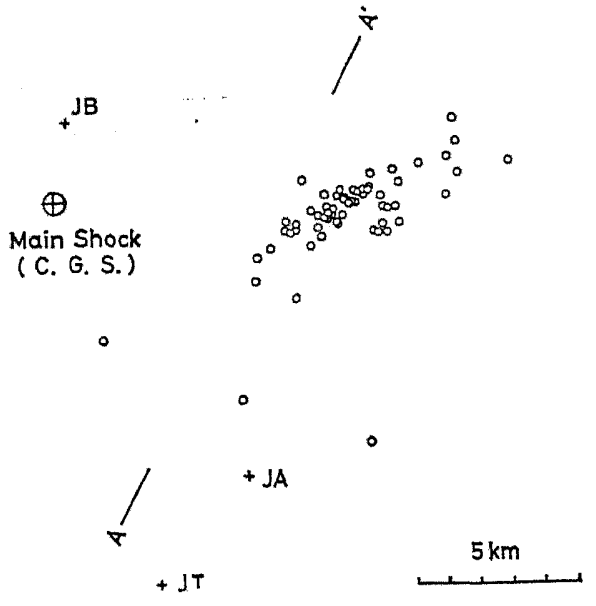

Fig. 7 (a). The distribution of the epicenters.

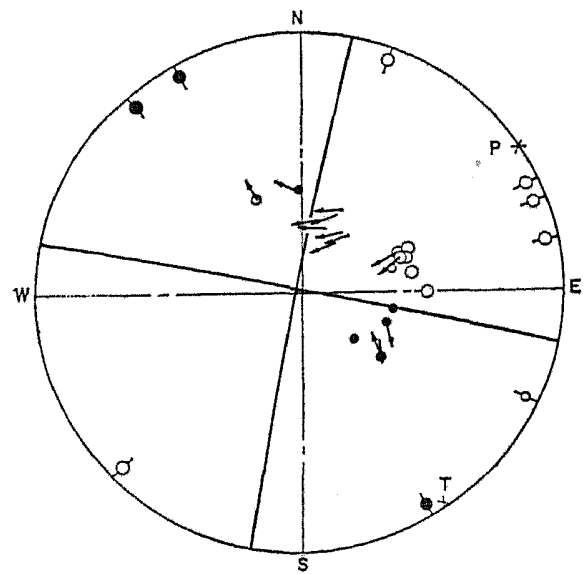

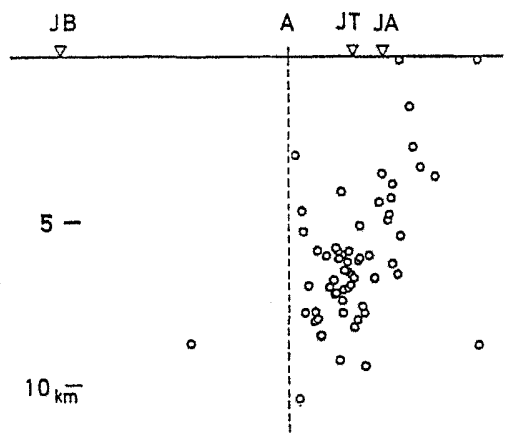

Fig. 7 (b). The distribution of the focal depths.

Fig. 8. $P$ and $S$ wave observations and focal mechanism solution from $S$ wave data with weight for the southeastern Nevada earthquake. (After T. Hirasawa)

records at both the stations for earthquakes of magnitude under -1.0 .

Therefore, only foci of ultra microearthquakes with magnitude over -1.0 were determined. Although the accuracy of the location of the foci is not evaluated, the distribution of foci varies very little from the present figure even if values of the velocities of $P$ and $S$ waves different from the above ones are assumed.

The result is shown in Figs. 7(a), (b). Figure 7 (a) represents the distribution of the epicenters and (b) the distribution of the focal depths. They show that the epicenters are distributed about $5 \mathrm{~km}$ apart from the main shock and focal depths are almost all within $10 \mathrm{~km}$ in depth from the surface. The trend of the distribution of the aftershock foci seems to correspond to the north-northeastward trending of general Basin and Range structure in this area the same as the result of the epicenter map of aftershocks determined by Cook et al. (1968). Focal mechanisms of this earthquake are described by HIRASAWA (1970) and TSAI and AKI (1971). The trend in the distribution of foci derived 
from our observed data agrees with the trend of one of the nordal lines in Hirasawa and Tsai and Aki. Figure 8 shows the result by Hirasawa.

\section{Conclusion}

Observations of aftershocks of a southeastern Nevada earthquake that occurred on August 16, 1966, were made in early April of 1967 at Caliente, Nevada.

The results of this expedition lead to the following conclusions.

1) About 2600 aftershocks per day were observed seven and a half months after the main shock.

2) A $b$ value determined to be 1.10 for the magnitude range from -1.1 to 0.2 .

3) The magnitude of the smallest events was estimated to be about -3.0 . The minimum value of ground noises was $0.6 \mu \mathrm{cm} / \mathrm{sec}$.

4) The trend of the distribution of the aftershock foci is parallel to the tectonic trending of Basin and Range structure and agrees with the trend of one of the nordal lines in focal mechanisms determined by Hirasawa and by Tsai and Aki. It is also pointed out that aftershocks with a very small magnitude takes place in the same region of rather large aftershocks determined by Cook et al.

It should be noted that a precise observation with the instruments of very high sensitivity in a short period expedition is sufficient to obtain general features of aftershock activity.

We would like to express our gratitude to Drs. A. Ryall, D. B. Slemmons, G. Boucher and L. Seeber for their close cooperation and assistance in various phases of this work.

Thanks are also due to Drs. T. Asada, J. Oliver and T. Matumoto for their kind advice and encouragement throughout this expedition.

This study was partly supported by the Japan Society for Promotion of Science and National Science Foundation in U.S.A.

\section{REFERENCES}

Boucher, G., L. SeEber, P. WARD, and J. Oliver, Microaftershock observations at the epicenter of a moderate-sized earthquake in Nevada (abstract), Trans. AGU, 48, 205, 1967.

Cook, L. K., R. B. SMirh, and J. L. WrLson, The southern Nevada-Utah border earthquakes of August and September 1966 (abstract), Trans. $A G U, 49,290,1968$.

HiRASAWA, T., Focal mechanism determination from $S$ wave observations of different quality, J. Phys. Earth, 18, 285-294, 1970.

Oliver, J., A. RYAll, J. N. BRUNe, and D. B. Slemmons, Microearthquake activity recorded by portable seismographs of high sensitivity, Bull. Seism. Soc. Amer., 56, 899-924, 1966.

RICHTER, C.F., An instrumental earthquake magnitude scale, Bull. Seism. Soc. Amer., 25, 1-32, 1935.

Ryall, A., D. B. Slemmons, and L.D. GeDney, Seismicity, tectonism, and surface faulting in the western United States during historic time, Bull. Seism. Soc. Amer., 56, 1105-1135, 1966.

Slemmons, D. B., A. E. Jones, and J. I. Gimletr, Catalog of Nevada earthquakes, 1852-1960, Bull. Seism. Soc. Amer., 55, 519-565, 1965.

TSAI, Y.B., and K. Akr, Amplitude spectra of surface waves from small earthquakes and underground nuclear explosions, J. Geophys. Res. 76, 3940-3952, 1971.

UTsu, T., A method for determining the value of $b$ in a formula $\log n=a-b M$ showing the magnitude-frequency relation for earthquakes (in Japanese), Geophys. Bull. Hokkaido Univ., 13, 99-103, 1965.

WATANABE, H., Determination of earthquake magnitude at regional distance in and near Japan Zisin Ser. II, 189-200, 1971 (in Japanese). 